\title{
Magnetometria aplicada na localização de estruturas potencialmente mineralizadas na região do distrito de Cangas, município de Poconé-MT.
}

\author{
Alfaro, A.Y.B., FAGEO-UFMT; Freitas, J.A., FAGEO-UFMT; Alves, M.F.M., FAGEO-UFMT; Fachin, S.J.S., FAGEO-UFMT;
}

Vasconcelos, B.R., Instituto de Geociências-UnB.

Copyright 2018, SBGf - Sociedade Brasileira de Geofísica

Este texto foi preparado para a apresentação no VIII Simpósio Brasileiro de Geofísica, Salinópolis, 18 a 20 de setembro de 2018. Seu conteúdo foi revisado pelo Comitê Técnico do VIII SimBGf, mas não necessariamente representa a opinião da SBGf ou de seus associados. É proibida a reprodução total ou parcial deste material para propósitos comerciais sem prévia autorização da SBGf

\section{Resumo}

O trabalho realizado na Província Aurífera da Baixada Cuiabana, distrito de Cangas, município de Poconé-MT, teve como objetivo a estimação de novos alvos para a exploração de ouro e a continuidade das lavras atuais. A mineralização ocorre associada à veios de quartzo que se apresentam discordantes, verticalizados a subverticalizados, com trend preferencial NE-SW, contidos nas rochas sedimentares do Grupo Cuiabá, metamorfizadas e dobradas na Fácies Xisto Verde. A execução deste trabalho utilizou o método magnetométrico de prospecção geofísica devido às propriedades ferromagnéticas de minerais associados ao ouro nos veios de quartzo. Foram realizados doze perfis com estações equidistantes de quinze metros entre si, totalizando 28,35 quilômetros lineares e 1890 pontos de leituras magnéticas. A totalidade de perfis e dados magnéticos observados produziu três padrões anômalos com potencialidade de prospecção por métodos diretos.

\section{Introdução}

A área de estudo, localizada no município de Poconé-MT, distrito de Cangas, distante de aproximadamente $90 \mathrm{Km}$ da Capital Cuiabá/MT, é muito conhecida por seu conteúdo aurífero e pelas amplas expedições executadas por bandeirantes em busca do ouro.
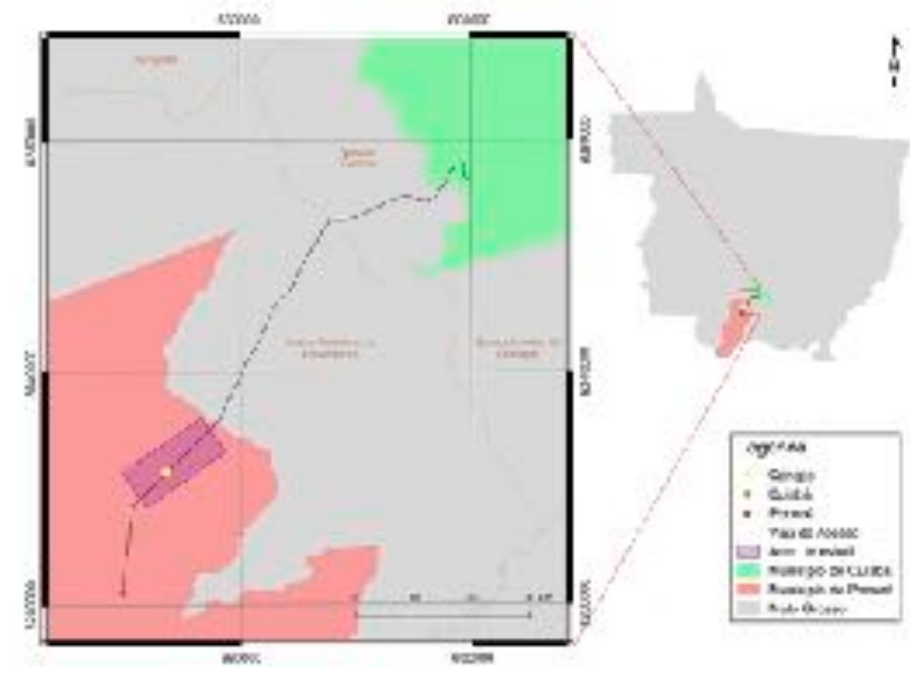

Figura 1 - Mapa de localização da área.

A exploração do ouro nesta localidade deu-se em dois ciclos, sendo o primeiro o responsável pelo povoamento da cidade de Cuiabá e seus entornos, e o segundo pela instalação de pequenas unidades de beneficiamento nas redondezas do município de Poconé. No início do segundo ciclo, tais empreendimentos cresceram de forma desordenada e órgãos públicos como o Departamento Nacional de Produção Mineral (DNPM) e a Secretaria de Estado do Meio Ambiente (SEMA) interviram com o objetivo de regularizá-los.

Contudo, mesmo com a regularização, a configuração atual dos modelos prospectivos na região se demonstra mecânica e dispendiosa, seja pelo grande volume de material amostrado, pelo tempo envolvido na busca de novas áreas ou pela alteração geomorfológica da região.

Assim, os empreendedores buscam novos métodos para localização de futuras cavas, bem como a continuidade das atuais, de maneira que sejam otimizadas e tenham o manejo adequado quanto aos aspectos ambientais.

Dessa forma, o trabalho desenvolvido apresenta os aspectos associados ao parâmetro magnético das rochas no distrito de Cangas e suas implicações na prospecção da região, visando melhores práticas para a localização do minério.

A relevância do estudo reside na escala de detalhe utilizada, que melhor caracteriza os veios de quartzo mineralizados da região, uma vez que a base base de dados aerogeofísicos disponibilizada pela Companhia de Pesquisa de Recursos Minerais (CPRM) para a Baixada Cuiabana (Projeto Aerogeofísico Cuiabá Escalas $1: 100.000$ e 1:250.000) não dispõe de resolução necessária para a identificação de estruturas com pequenas dimensões.

A escolha do método deve-se à ocorrência de associações mineralógicas ferromagnéticas com o ouro, que tem como consequência a produção de anomalias no campo magnético capazes de serem lidas por sensores denominados magnetômetros.

\section{Metodologia}

Durante a etapa preparatória, foram realizados levantamentos bibliográficos à cerca do contexto geológico e dos fundamentos teóricos do método magnetométrico. Já etapa de aquisição de dados representa a parte da coleta de dados em campo, enquanto que a etapa de gabinete foi a resultante da criação dos gráficos e dos mapas.

A coleta de dados foi realizada em três campanhas, em escala de detalhe com leituras a cada 15 metros ao longo do caminhamento. Os perfis foram orientados ortogonalmente aos trends mineralizados de direção $\mathrm{N} 40 \mathrm{E}$, com comprimento variando entre $1,5 \mathrm{~km}$ e $2,5 \mathrm{~km}$ 
de extensão, paralelos entre si, equidistantes em aproximadamente 500 metros.

Apenas um magnetômetro foi utilizado, havendo a necessidade de interromper o levantamento periodicamente, em intervalos de no máximo uma hora, para que a medida fosse repetida na estação base. Desta forma, pôde-se, ao menos de forma aproximada, reconstituir a variação diurna do campo magnético durante o período que o magnetômetro móvel procedeu as medições.

A fim de obter gráficos e mapas livres de ruídos, foram aplicadas correções para os efeitos da variação diurna. Então, o campo corrigido foi calculado e, adiante, no site do Observatório Nacional (ON) obteu-se o datum local, por meio do acesso ao sítio eletrônico https://daed.on.br/astro/ linhas-de-forca para o cálculo do campo residual, que por sua vez foi utilizado para a geração dos gráficos de anomalias magnéticas a partir do software Microsoft Office 2018.

Para a construção do mapa de localização e vias de acesso, utilizou-se os softwares ArcGIS® 10.5.1 e QGIS® 2.18 .13 , ambos configurados com o sistema de coordenadas WGS84 zona 21S. A modelagem de dados e criação do mapa final com as anomalias magnéticas de interesse fez-se pelo uso do Geosoft Oasis Montaj. Todos os softwares foram licenciados e providos pela Universidade Federal de Mato Grosso no Laboratório de Geociências.

\section{Resultados}

O Mapa Geológico e Perfis Magnéticos (Figura 2) tem a finalidade de obter a melhor visualização espacial dos dados de campo e da logística do trabalho desenvolvido.

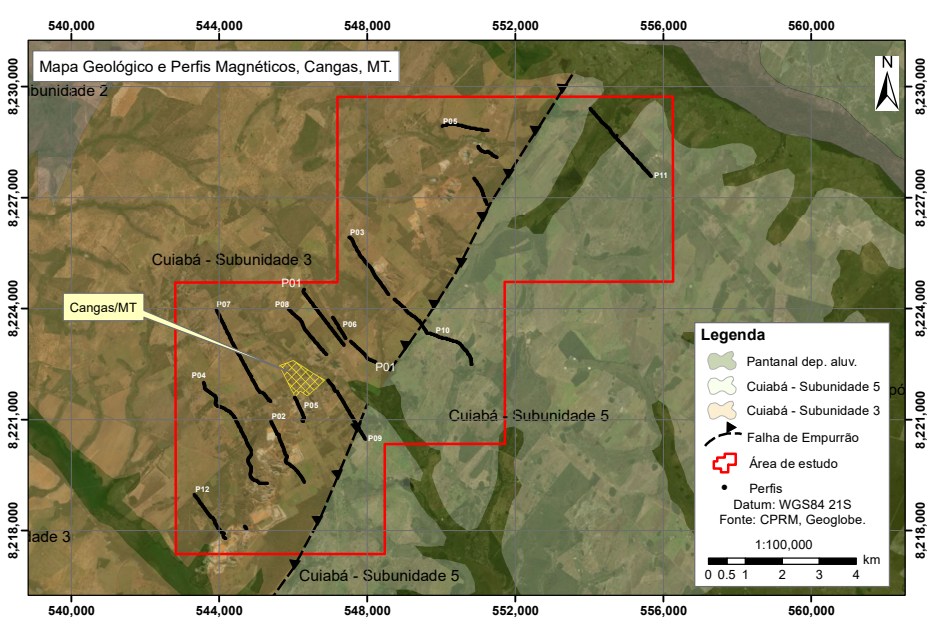

Figura 2 - Mapa da área de estudo compilando os perfis 1 a 12 e as subunidades 3 e 5 de Luz et al.(1980) do Grupo Cuiabá que ocorrem na área de estudo.

São demonstrados os limites da área estudada, o Lineamento Cangas-Poconé marcado, pela falha de empurrão da região, e a distribuição da malha amostral. Os perfis estão dispostos na direção aproximada de N60W, ou seja, perpendiculares ao lineamento mineralizado de direção N40E. Sabe-se que os litótipos aflorantes do Grupo Cuiabá na área de estudo são pertencentes às subunidades 3 e 5 de Luz et al. (1980).
Com os Gráficos Magnéticos, criados a partir dos dados coletados em campo, foi possível observar a variação do campo magnético residual e usá-la para a confecção do Mapa do Campo Magnético Anômalo (Figura 3).

$\mathrm{Na}$ confecção deste mapa os dados foram tratados e gerou-se um banco de dados no formato .gdb, capaz de ser lido pelo software Geosoft Oasis Montaj. Os sinais magnéticos obtidos para a área de Cangas estão relacionados à presença de magnetita, que por sua vez ocorre localmente como associação mineralógica nas estruturas rochosas da Baixada Cuiabana. Para os valores mais consideráveis do campo residual, utilizou-se os tons mais rosados, enquanto que para os valores menos significativos, tons anilados.

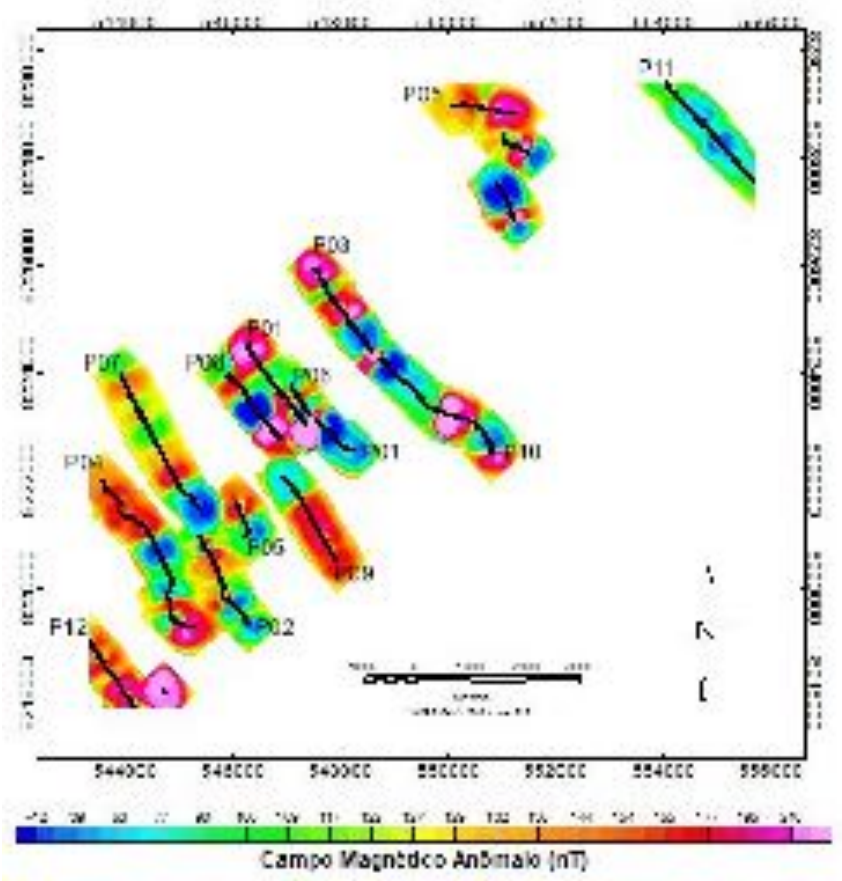

Figura 3 - Mapa do campo magnético anômalo georreferenciado na região do levantamento geofísico. Tons rosados indicam valores altos para o sinal magnético e tons anilados indicam valores baixos do campo residual.

Diante do Mapa Magnético Anômalo, foi possível produzir - mapa de Isolíneas Magnéticas Anômalas (Figura 4). A partir do intervalo de valores entre 132nT e 240nT, classificou-se o campo residual em três categorias, sendo elas Padrão 1, 2 e 3 . O padrão 1 de cor vermelha representa a maior evidência de minerais magnéticos com intervalos de $196 n$ T à $240 n T$, obtendo a prioridade de investigação por meios diretos. O Padrão 2 de cor amarela representa os pontos com valores do campo residual medianos, oscilando entre 159nT e 195nT. Já o Padrão 3 de cor verde, a resposta magnética é a menos relevante deste mapa, representada pelo intervalo de valores entre $132 \mathrm{nT}$ e 158nT. Nota-se que independentemente do valor do campo residual, há a possibilidade da mineralização ocorrer mesmo nas porções do padrão 3 , porém sua ocorrência é menos provável que nas porções dos padrões 1 e 2. 


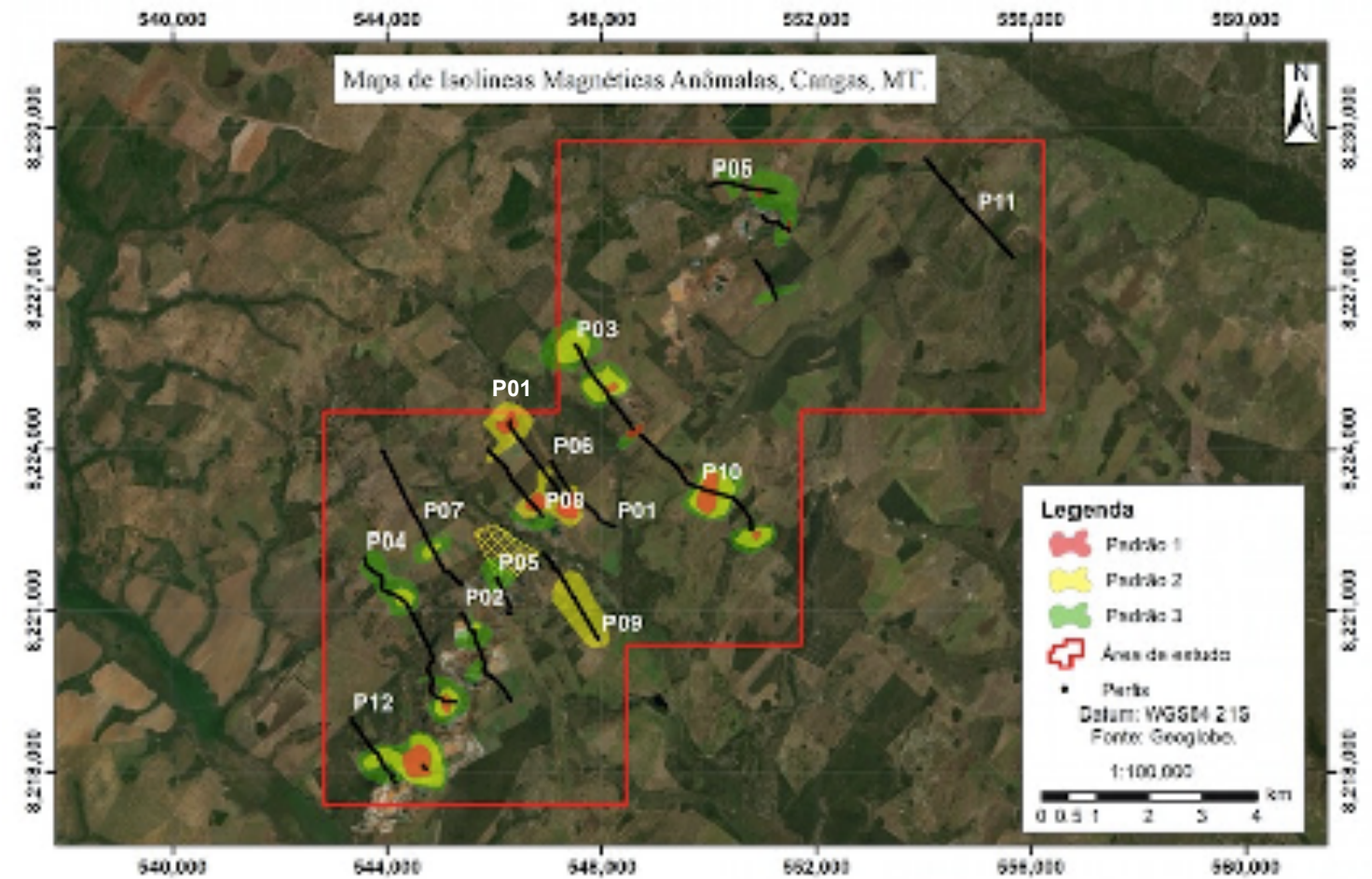

Figura 4 - Mapa de Isolíneas Magnéticas Anômalas do distrito de Cangas, município de Poconé, MT.

\section{Discussão}

Medidas magnéticas podem fornecer informações sobre alinhamentos estruturais, contatos geológicos, limites de bacias sedimentares e parâmetros de um corpo mineralizado. Entretanto, a interpretação de anomalias magnéticas ainda é de muita complexidade devido aos erros e problemas que podem surgir, como por exemplo a ambiguidade de leitura e a presença de magnetização remanescente.

Anomalias magnéticas de corpos finitos invariáveis têm sua forma controlada pela direção da magnetização (Kearey et al., 2002), ou seja, corpos de formas idênticas podem gerar anomalias diferentes. Porém, a existência de remanescência pode modificar a forma da anomalia, a ponto da resposta teórica calculada para o modelo da fonte ser completamente diferente da anomalia observada. Por meio de revisões bibliográficas, nota-se que alguns parâmetros como a profundidade das fontes anômalas são possíveis de se obter mais facilmente a partir da compilação com outros métodos de prospecção. Esta combinação aumenta a taxa de confiabilidade dos produtos finais para um mesmo perfil de anomalia. Entretanto, alguns pesquisadores trabalham no desenvolvimento de métodos matemáticos e computacionais que podem vir a estimar tais parâmetros.

Mesmo não sendo usual, autores como Spector \& Grant (1970) dizem ser possível estimar relativamente a profundidade de corpos geológicos de acordo com as anomalias obtidas, ou seja, em anomalias magnéticas causadas por estruturas rasas, ocorre uma predominância de componentes com comprimentos de onda curtos em contraste com as resultantes de fontes mais profundas.

No que se refere à geologia, Kearey et al. (2002) afirma que áreas de coberturas sedimentares com embasamento relativamente profundos são normalmente representadas por contornos magnéticos suaves, refletindo estruturas do embasamento e contrastes de magnetização. Já os terrenos ígneos e metamórficos geram anomalias bastante complexas, e os efeitos das feições geológicas profundas podem ser ofuscados por anomalias de comprimentos de onda curtos originadas próximo à superfície (Kearey et al., 2002).

\section{Conclusão}

Para a interpretação dos dados, levou-se em conta a localização dos perfis e os valores magnéticos anômalos, os quais foram zonados em Padrões 1, 2 e 3 . Os locais de maior significância puderam ser alocados onde há a predominância de sinais magnéticos de alto valor, representados pelo Padrão 1 de cor avermelhada, $46 \mathrm{com}$ assinaturas magnéticas entre 144 e $200 \mathrm{nT}$, correspondente às regiões dos perfis 1,6 e 8 , bem como parte dos perfis 10 e 12

Fica evidente, ao comparar as Figuras 2 e 3, que há maior contribuição magnética nas porções constituídas por rochas da subunidade 3 do Grupo Cuiabá, representadas por diamictitos e filitos com níveis de hematita e magnetita, que apresentam maior concentração minerais magnéticos em relação às outras subunidades presentes na área, como descreve a literatura de Luz et al. (1980).

Os levantamentos terrestres realizados na região estudada também foram efetuados por outros pesquisadores e obteve-se similaridade com os padrões encontrados, indicando que esta ferramenta pode ser usada como complementação de campanhas prospectivas na baixada cuiabana. Assim, a metodologia aqui adotada é aplicável às áreas da Baixada Cuiabana, tal como aos garimpos da 
região, e significativamente visa a redução dos custos quanto à amostragem e quanto às buscas por novas estruturas mineralizadas.

Por fim, considera-se que para a região, o mapeamento de detalhe realizado necessita de adensamento em sua malha amostral, da mesma maneira que necessita de processamentos mais complexos, em ordem de estimar outros parâmetros das fontes anômalas como, por exemplo, o cálculo da profundidade das anomalias magnéticas observadas.

\section{Agradecimentos}

Agradecemos à Cooper Poconé pelo auxílio nas etapas de campo, essenciais para o cumprimento deste trabalho, em particular ao Geólogo André Molina. Agradecemos, também, às turmas de Geologia UFMT 2013 e 2014 pelas colaborações e aos funcionários da UFMT conectados direta ou indiretamente na confecção deste estudo.

\section{Referências}

Grant, F. S. \& West, G. F. 1965. Interpretation Theory in Applied Geophysics. pp. xx +583 , figs. McGraw-Hill Book Co., New York.

Kearey, P.; Brooks, M.; Hill, I. 2002. Introduction to Geophysical Exploration, 3a edição. Blackwell Publications, Oxford.

Luz, J. S.; Oliveira, A. de M.; Souza, J. O.; Motta, J. F. M.; Tanno, L. C.; Carmo, L. S.; Souza, N. B. de; Abreu Filho, W. 1980. Projeto Coxipó. Goiânia, DNPM/CPRM, Relatório Final. v.1, 136p.

Spector, A. \& Grant, F. S. 1970. Statistical Models for Interpretation Aeromagnetic Data. Geophysics, 35, 293-302. 